TAO, Vol. 15, No. 3, 361-370, September 2004

\title{
Changes of Geomagnetic Total Field and Occurrences of Earthquakes in Taiwan
}

\author{
Chieh-Hung Chen ${ }^{1}$, Jann-Yenq Liu ${ }^{2, *}$, Horng-Yuan Yen ${ }^{1}$, \\ Xiaoping Zeng ${ }^{3}$ and Yih-Hsiung Yeh $^{4}$
}

(Manuscript received March 2004, in final form 16 June 2004)

\begin{abstract}
This paper examines variations in the geomagnetic total field recorded by eight stations in Taiwan from 1989 to 2001. A comparison of data from the international geomagnetic reference field (IGRF) and the eight stations shows that the annual change rates of the field reduce down to $\pm 5 \mathrm{nT} / \mathrm{yr}$ in 1997.9. Spatial and temporal analyses demonstrate that a zero isoporic zone (ZIZ) tends to lead to $M \geq 6.0$ earthquakes within 2 years in the Taiwan area.
\end{abstract}

(Key words: Geomagnetic field, Magnetometer, Earthquake, Zero isoporic zone)

\section{INTRODUCTION}

Electromagnetic phenomena associated with seismic activity have been extensively discussed (Hayakawa and Fujinawa 1994; Pulinets 1998; Molchanov and Hayakawa 1998; Hayakawa 1999; Freund 2000). Qi (1981) developed a model to simulate geomagnetic variations on the Earth's surface caused by underground anomalous conductivity. Zeng et al. (2001) studied a large numbers of cases in various places and found about $80 \%$ of $\mathrm{M} \geq 6.0$ earthquakes occurred within 9 months to 2.5 years after the appearances of a zero isoporic zone (ZIZ), which is defined as the annual change rate of geomagnetic parameters to be less than or equal to $\pm 5 \mathrm{nT} / \mathrm{yr}$. Although many individual cases and segmented data in China, Japan and

\footnotetext{
1 Institute of Geophysics, National Central University, Chung-Li, Taiwan, ROC

2 Institute of Space Science, National Central University, Chung-Li, Taiwan, ROC

3 Institute of Geophysics, China Seismological Bureau, Beijing, China

${ }^{4}$ Institute of Earth Sciences, Academia Sinica, Taipei, Taiwan, ROC

* Corresponding Author address: Prof. Jann-Yeng Liu, Institute of Space Science, National Central University, Chung-Li, Taiwan, ROC; E-mail: jyli@jupiter.ss.ncu.edu.tw
} 
Turkey have been reported, the geomagnetic fields were not continuously recorded and systematically examined.

Taiwan is located in an active part of the Circum-Pacific seismic belt. The interaction between the northwestward-moving Philippine Sea plate and the Eurasian plate depicts an intense and complicated geological structure, and results in large earthquakes in the Taiwan collision zone (Wang et al. 2002). Earthquakes in the Taiwan area are routinely documented and published by the Central Weather Bureau (CWB). In addition, a network of eight magnetometer stations equipped with continuous recording systems was established in 1989 by the Institute of Earth Sciences, Academia Sinica to monitor the geomagnetic total field of Taiwan island wide (Yen et al. 2004). Continuous records provide us a good chance to examine the relationship between annual change rates of the total geomagnetic field and occurrences of earthquakes in Taiwan from 1989 to 2001.

\section{OBSERVATION AND DATA ANALYSIS}

Figure 1 illustrates the locations of the eight magnetometer stations and the epicenters of $M \geq 6.0$ earthquakes (Table 1) that have occurred in the Taiwan area during 1989-2002.6. The proton precision magnetometers (GeoMetrics, Model G856) at the stations record absolute and relatively high-resolution $(0.1 \mathrm{nT})$ measurements of the geomagnetic field. The Lunping $\left(\mathrm{LP}, 25.0^{\circ} \mathrm{N}, 121.2^{\circ} \mathrm{E}\right.$ ) station was equipped in a seismically quiet area, while the Liyutan (LY, $\left.24.3^{\circ} \mathrm{N}, 120.767^{\circ} \mathrm{E}\right)$ and the Tsengwen $\left(\mathrm{TW}, 23.3^{\circ} \mathrm{N}, 120.5^{\circ} \mathrm{E}\right)$ stations are located in western Taiwan. The other stations, Neicheng ( $\left.\mathrm{NC}, 24.7^{\circ} \mathrm{N}, 121.7^{\circ} \mathrm{E}\right)$, Hualien (HL, $24.1^{\circ} \mathrm{N}$, $\left.121.6^{\circ} \mathrm{E}\right)$, Yuli $\left(\mathrm{YL}, 23.4^{\circ} \mathrm{N}, 121.3^{\circ} \mathrm{E}\right)$, Taitung (TT, $\left.22.8^{\circ} \mathrm{N}, 121.1^{\circ} \mathrm{E}\right)$ and Hengchun $(\mathrm{HC}$, $\left.21.9^{\circ} \mathrm{N}, 120.8^{\circ} \mathrm{E}\right)$ are located in eastern Taiwan. The sampling rate at the LP station is at 5minute intervals, while the rest stations have 10-minute intervals (for detail see, Yen et al. 2004).

Let $T$ be the total intensity of the geomagnetic field recorded at each station. The hourly value can be derived by averaging the raw data in one hour, the daily value be obtained by averaging the hourly values in one day, and then, the monthly value is calculated by averaging the daily values in one month (Chapman 1940). We therefore obtain the annual mean by averaging the monthly values in one year, $T_{i}$, where $i$ denotes the year.

On the other hand, for each month, the method of finding out the discernible characteristic indication of geomagnetic field related to earthquakes can be found by solving for anthe annual change rate of $\dot{T}$,

$$
\dot{T}_{n, m}=\frac{\Delta T}{\Delta t}=\frac{\operatorname{Mean}\left(\sum_{m=-6}^{6} T_{n+1, m}\right)-\operatorname{Mean}\left(\sum_{m=-6}^{6} T_{n, m}\right)}{1(\text { year })},
$$

where $n$ is the yearly order, and $m$ is the monthly order. For comparison, we also calculate the 
corresponding geomagnetic field and associated $\dot{T}$ for each station by employing the international geomagnetic reference field (IGRF) model (Barton 1997).

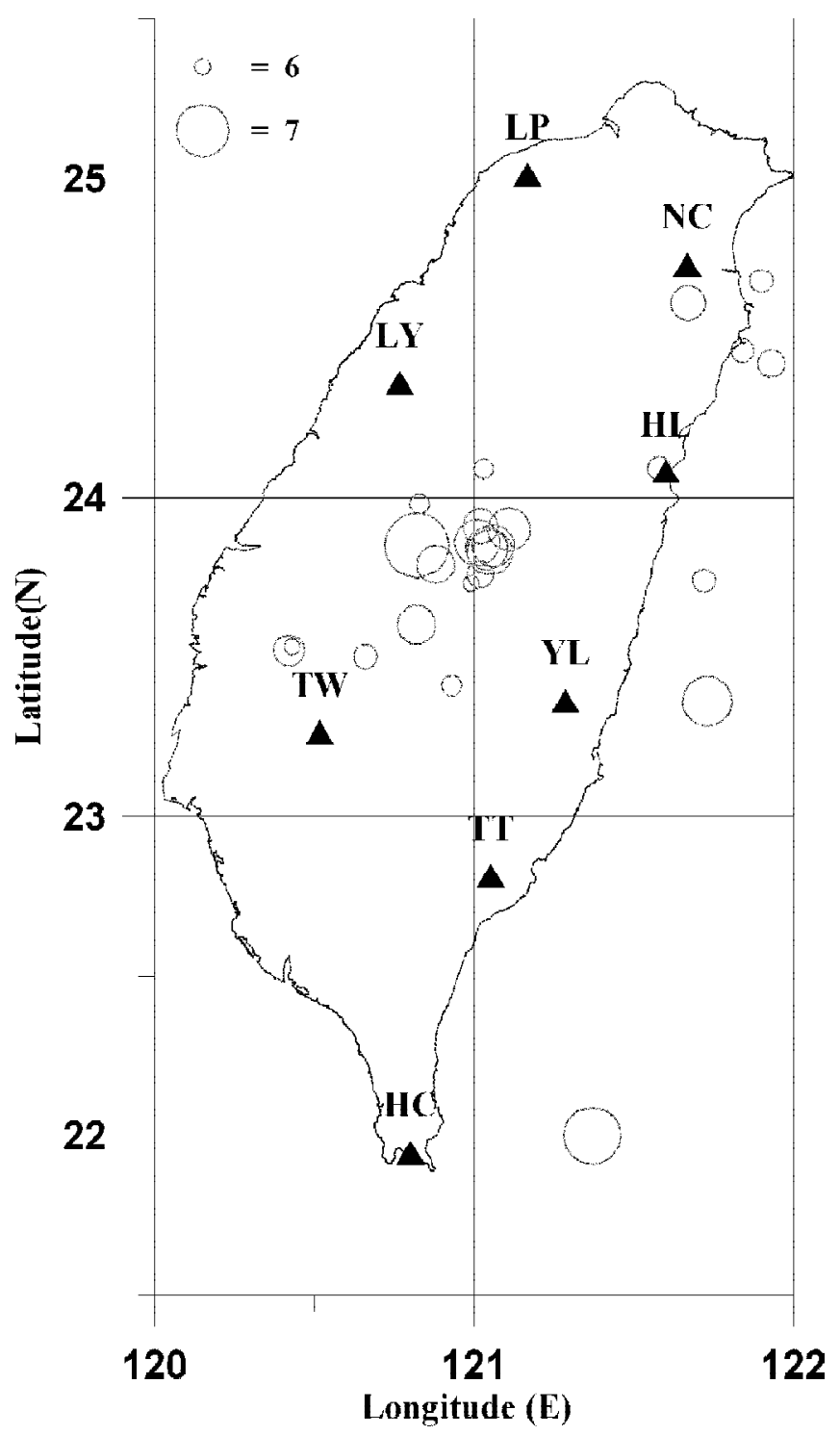

Fig. 1. The locations of the geomagnetic stations and earthquakes. The triangles denote the locations of the eight geomagnetic stations. The open circles represent the $M \geq 6.0$ earthquakes (see Table 1 for the day, depth, magnitude and locations of earthquakes). 
Table 1. Occurrence day, depth, magnitude and locations for the $M \geq 6.0$ earthquakes in this study.

\begin{tabular}{ccrrccc}
\hline Year & Month & Day & $\begin{array}{r}\text { Depth } \\
(\mathrm{Km})\end{array}$ & $\begin{array}{c}\text { Magnitude } \\
\left(\mathrm{M}_{\mathrm{L}}\right)\end{array}$ & $\begin{array}{c}\text { Longitude } \\
(\mathrm{E})\end{array}$ & $\begin{array}{c}\text { Latitude } \\
(\mathrm{N})\end{array}$ \\
1994 & 6 & 5 & 5.3 & 6.2 & $121.84^{\circ}$ & $24.46^{\circ}$ \\
1995 & 6 & 25 & 39.9 & 6.5 & $121.67^{\circ}$ & $24.61^{\circ}$ \\
1996 & 9 & 5 & 14.8 & 7.1 & $121.37^{\circ}$ & $22.00^{\circ}$ \\
1998 & 7 & 17 & 2.8 & 6.2 & $120.66^{\circ}$ & $23.50^{\circ}$ \\
1999 & 9 & 20 & 8.0 & 7.3 & $120.82^{\circ}$ & $23.85^{\circ}$ \\
1999 & 9 & 20 & 19.7 & 6.1 & $120.83^{\circ}$ & $23.98^{\circ}$ \\
1999 & 9 & 20 & 3.0 & 6.1 & $121.03^{\circ}$ & $24.09^{\circ}$ \\
1999 & 9 & 20 & 2.2 & 6.5 & $121.02^{\circ}$ & $23.91^{\circ}$ \\
1999 & 9 & 20 & 3.5 & 6.6 & $120.88^{\circ}$ & $23.79^{\circ}$ \\
1999 & 9 & 20 & 1.0 & 6.7 & $121.06^{\circ}$ & $23.85^{\circ}$ \\
1999 & 9 & 20 & 1.1 & 6.7 & $121.04^{\circ}$ & $23.84^{\circ}$ \\
1999 & 9 & 20 & .3 & 6.6 & $120.82^{\circ}$ & $23.60^{\circ}$ \\
1999 & 9 & 22 & 15.6 & 6.8 & $121.05^{\circ}$ & $23.83^{\circ}$ \\
1999 & 9 & 22 & 8.9 & 6.3 & $121.02^{\circ}$ & $23.76^{\circ}$ \\
1999 & 9 & 22 & 23.5 & 6.0 & $120.99^{\circ}$ & $23.73^{\circ}$ \\
1999 & 9 & 25 & 9.9 & 6.8 & $121.01^{\circ}$ & $23.86^{\circ}$ \\
1999 & 10 & 22 & 16.6 & 6.4 & $120.42^{\circ}$ & $23.52^{\circ}$ \\
1999 & 10 & 22 & 16.7 & 6.0 & $120.43^{\circ}$ & $23.53^{\circ}$ \\
1999 & 11 & 1 & 31.3 & 6.9 & $121.73^{\circ}$ & $23.36^{\circ}$ \\
2000 & 6 & 10 & 16.2 & 6.7 & $121.11^{\circ}$ & $23.90^{\circ}$ \\
2000 & 7 & 28 & 7.3 & 6.1 & $120.93^{\circ}$ & $23.41^{\circ}$ \\
2000 & 9 & 10 & 17.7 & 6.2 & $121.58^{\circ}$ & $24.09^{\circ}$ \\
2001 & 6 & 14 & 17.3 & 6.3 & $121.93^{\circ}$ & $24.42^{\circ}$ \\
2002 & 2 & 12 & 30.0 & 6.2 & $121.72^{\circ}$ & $23.74^{\circ}$ \\
2002 & 5 & 15 & 5.0 & 6.2 & $121.90^{\circ}$ & $24.68^{\circ}$ \\
\hline & & & & & & \\
\hline
\end{tabular}

\section{RESULTS AND INTERPRETATION}

Figure 2 illustrates the annual means of the total fields, $T_{i}$, observed and derived from the IGRF models at each station from 1988 to 2001. Although there are some systematic differences, less than $100 \mathrm{nT}$, between the observation and derivation, the two total fields generally yield similarly increased tendencies before 1997 . It can be seen that the overall annual change rates, $\left(T_{1997}-T_{1988}\right) /(1997-1988)$ of the two fields lie between 24.8 and $29.7 \mathrm{nT} / \mathrm{yr}$ from 1988 to 1997. However, after 1997 the overall observed annual change rates tend to be smaller than those derived. Importantly, after 1997 and except for the YL station (9.3 nT/yr), almost all the observed annual change rates are less than $|5| \mathrm{nT}$ and meet the criteria of athe zero isoporic (ZI) as outlined by Zeng et al. (2001). 


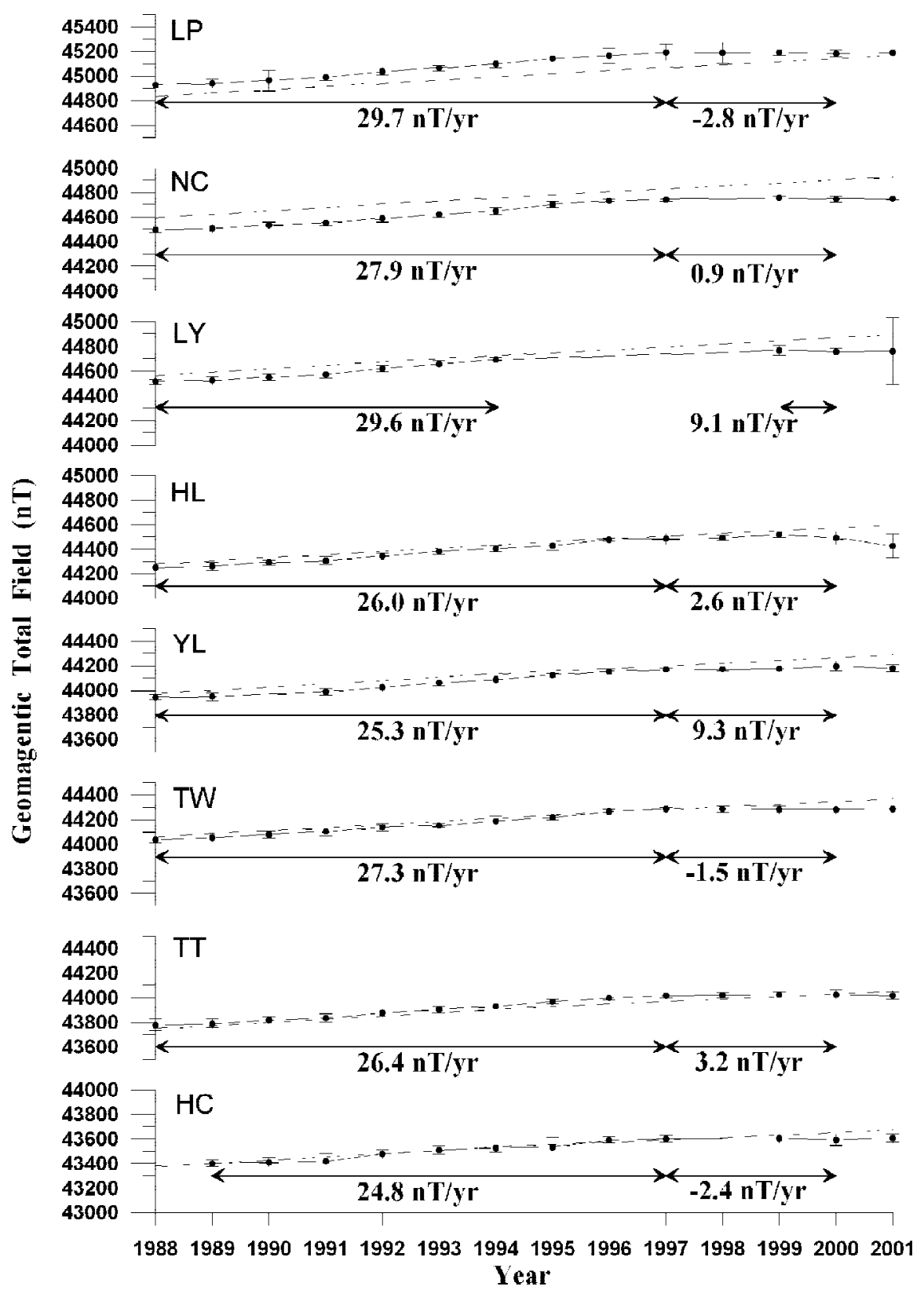

Fig. 2. Temporal variations of the geomagnetic total field during 1988 - 2001. The solid and dashed lines denote the yearly value of the observed and IGRF field, respectively. The error bars are the standard deviation of the yearly values. 
Zeng et al. (2001) found that the ZIZ tends to presage $M \geq 6.0$ earthquakes by about 9 months to 2.5 years. To see if this is truly the case, Fig. 3 displays the contours of the observed annual change rates between adjacent years, $\left(T_{i+1}-T_{i}\right) / 1$, of the eight stations and the number of $\mathrm{M} \geq 6.0$ earthquakes that occurred in following 9 months to 2.5 years. It can be seen that the observed annual change rates are generally larger than $15 \mathrm{nT}$ before 1996 . However, after 1996 - 1997 the ZIZ begins to appear and the observed annual change rate around HL station is still as small as $4.6 \mathrm{nT} / \mathrm{yr}$. After 1997, the earthquakes start to appear around the ZIZ, and are the most pronounced feature in 1999 - 2000.

The area of Taiwan is relatively small and therefore this allows us to evaluate the temporal variations of the overall, $\dot{T}$, and is derived by averaging the values of the eight stations. Figure 4 illustrates that the long term relationship between ZIZ in the $\dot{T}$ and occurrences of the $\mathrm{M} \geq 6.0$ earthquakes which clearly reveals the significant differences in the $\dot{T}$ before and after the large earthquakes during 1989 - 2002.6. The $\dot{T}$ varies between 15 and $45 \mathrm{nT}$ during 1989 - 1996.9 but sharply decreases and reaches the ZI in 1997.9 when the earthquake number also suddenly increases and reaches its maximum value of 12 in 1999.9. A detailed study shows the ZI leads the Chi-Chi earthquake $\left(9 / 21 / 1999, M_{L}=7.3\right)$ and aftershocks by 2 years. By contrast, the overall IGRF $\dot{T}$ yields constant values of 27 and $22 \mathrm{nT}$ before and after 1995. After the Chi-Chi earthquake, the $\dot{T}$ departs from the ZI $(\leq|5| \mathrm{nT})$ and further goes down to $-6.1 \mathrm{nT} / \mathrm{yr}$ in 2000.12, when the earthquakes also become rare.

\section{DISCUSSION AND CONCLUSION}

Zeng et al. (2002) found the strong earthquakes, Tangshan $(7 / 28 / 1976, \mathrm{Ms}=7.8)$ and Haicheng $(2 / 04 / 1975, \mathrm{Ms}=7.3)$ in China, occurred within 2.5 years after the appearance of ZIZ and the Ms $\geq 6.0$ earthquakes (1966.1 - 1969.12) in Turkey occurred within one year after the change rate in the horizontal intensity component of the geomagnetic field approached zero (Ispir et al. 1976). Eighty percent (80\%) of the earthquakes in Japan from 1954 to 1966 occurred within 2.5 years after the appearance of the ZIZ in the horizontal intensity component of the geomagnetic field (Tazima et al. 1976). Results in Figs. 3 and 4 show that the geomagnetic signature of the ZIZ tends to precede the Chi-Chi earthquake and its aftershocks by about 2 years, which agrees with the previous observations.

Qi (1981) found geomagnetic variations on the Earth's surface resulting from underground anomalous conductivity. Zeng et al. (2002) suggested that before the large earthquake, the fluid expended or compressed in the crust, which resulted in a subterranean equivalent planner current at a certain depth $(10-20 \mathrm{~km})$ in the coming epicentral region. In addition, they also developed a planner current model by taking the underground and ionospheric current systems into consideration to simulate the change of magnetic field on the Earth surface. Though the model was relatively coarse, the simulated the changes of the magnetic field reveal the ZIZ phenomena before a large earthquake. Meanwhile Chen and Chen (2000) observed a low resistivity anomaly, less than $10 \mathrm{ohm}-\mathrm{m}$, with depth ranging about $10-15 \mathrm{~km}$ during the ChiChi earthquake. They suggest the low resistivity anomaly to be related to underground fluids.

Results in this paper show that the magnetometer observations and IGRF simulations 

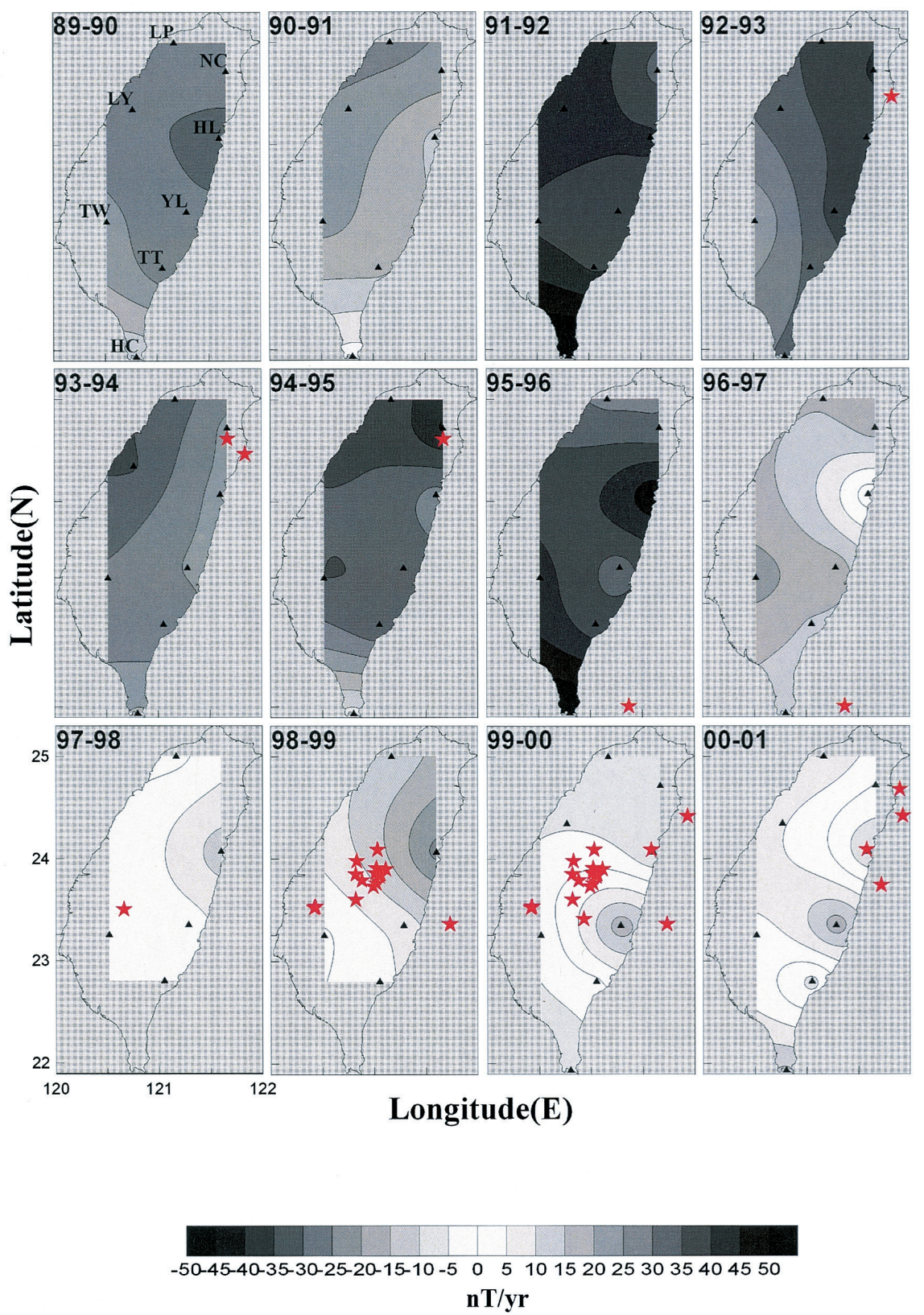

Fig. 3. The year-by-year isoporic diagrams of annual change rates in the geomagnetic total field between adjacent years from 1989 to 2001. The star symbols denote the locations of the $M \geq 6.0$ earthquakes occurring 9 - 30 months after the appearance of the ZIZ. Note that the earthquakes are plotted from 1989.9 to 2002.6 . 


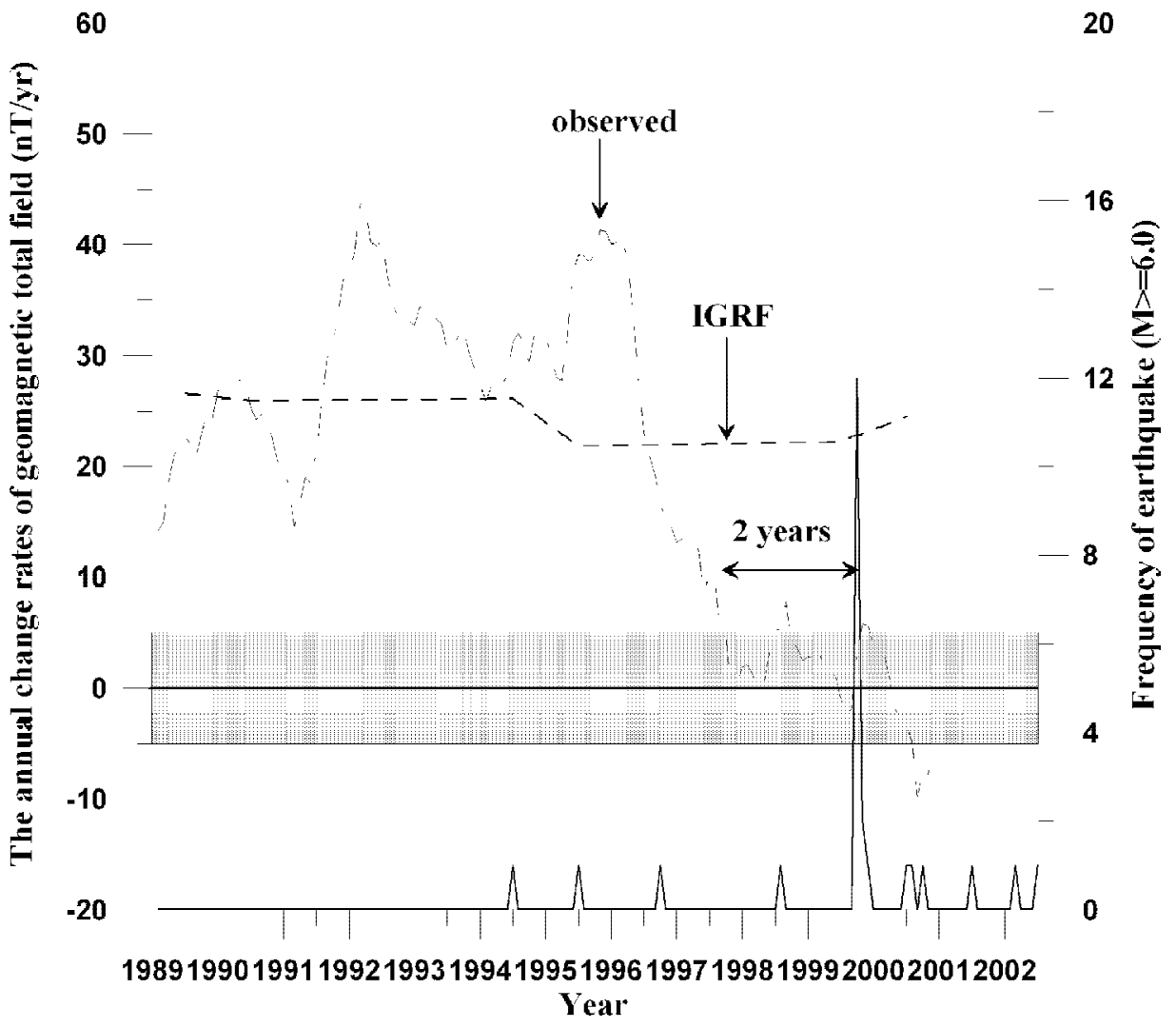

Fig. 4. The time and rate of changes of the observed and IGRF geomagnetic field as well as the number of $M \geq 6.0$ earthquakes, 1989.9-2002.6. The dotdashed line denotes the observed rates obtaining by averaging the data of the eight stations, while the dashed line represents the IGRF results. The solid line is the monthly number of $M \geq 6.0$ earthquakes.

yield similarly increased tendencies before 1997 (Figs. 2 and 4). However, after 1997 the observed time rate of changes in the geomagnetic field become much smaller than those of the IGRF, which suggests underground structures together with their conductivity (or resistivity) and currents before large earthquakes around the magnetometers start to change and modify near-by geomagnetic fields on the Earth's surface.

Although the detailed mechanisms are not fully understood, the previous observations and simulation (Chen and Chen 2000; Zeng et al. 2002; Qi 1981) as well as current results indicate the conductivity of the crust and the current systems in both underground and the 
ionosphere to be important to the ZIZ phenomena. In conclusion the long-term continuous observations of the eight magnetometers show that the spatial and temporal signatures in the zero isoporic zone (ZIZ) tend to lead $M \geq 6.0$ earthquakes withinby 2 years in the Taiwan area.

Acknowledgements The authors wish to thank the Institute of Earth Sciences at Academia Sinica and the Central Weather Bureau in Taiwan for providing the geomagnetic data and the earthquake catalog. We thank two reviewers for helpful comments. This research was partially supported by the Ministry of Education Grant 91-N-FA07-7-4 and the iSTEP project of the National Central University.

\section{REFERENCE}

Barton, C. E., 1997: International Geomagnetic Reference Field: The Seventh Generation.J. Geomag. Geoelectr., 49, 123-148.

Chapman, S., and J. Bartels, 1940: Geomagnetism, Oxford: The Charendon Press, 1049p.

Chen, C. S., and C. C. Chen, 2000: Magnetotelluric Soundings of the Source Area of the 1999 Chi-Chi Earthquake in Taiwan: Evidence of Fluids at the Hypocenter. TAO, 11, 679688.

Freund, F., 2000: Time-resolved study of charge generation and propagation in igneous rocks. J. Geophys. Res., 105, 11001-11019.

Hayakawa, M., and Y. Fujinawa (Eds.), 1994: Electromagnetic Phenomena Related to Earthquake Prediction. TERRAPUB, Tokyo, 667p.

Hayakawa, M. (Ed.), 1999: Atmospheric and Ionospheric Electromagnetic Phenomena Associated with Earthquakes. TERRAPUB, Tokyo, 997p.

Ispir, Y., A. M. Isikara, and H. Ozden, 1976: Variation in the local magnetic constant and conductivity of Turkey. J. Geomag. Geoelectr., 28, 137-143

Molchanov, O. V., and M. Hayakawa, 1998: Subionospheric VLF signal perturbations possibly related to the earthquake. J. Geophys. Res., 103, 17489-17504.

Pulinets, S. A., 1998: Seismic activity as a source of ionospheric variability. Adv. Space Res., 22, 903-906.

Qi, G., 1981: Anomalies of short-period geomagnetic variations and distribution of high conductivity layer in the Bohai Sea area. Scientia Sinica, 25, 214-226 (in Chinese).

Tazima M., H. Mizuno, and M. Tanaka, 1976: Geomagnetic secular change anomaly in Japan. J. Geomag. Geoelectr., 28, 137-143.

Wang, C., C. P. Huang, L. Y. Ke, W. J. Chien, S. K. Hsu, C. T. Shyu, W. B. Cheng, C. S. Lee, and L. S. Teng, 2002: Formation of the Taiwan Island as a Solitary Wave along the Eurasian Continental Plate Margin: Magnetic and Seismological Evidence.TAO, 13, 339-354.

Yen, H. Y., C. H. Chen, Y. H. Yeh, J. Y. Liu, C. R. Lin, and Y. B. Tsai, 2004: Geomagnetic fluctuations during the 1999 Chi-Chi earthquake in Taiwan. EPS, 56, 39-45. 
Zeng, X., Y. Lin, C. Xu, and S. O. Yang, 2001: Turning changes in evolution of geomagnetic field and infrastructural analysis of earthquake prediction. Kybernetes- Int. J. Systems \& Cybernetics, 30, 365-377.

Zeng, X., M. Hayakawa, Y. Lin, and C. Xu, 2002: Infrastructural analysis of geomagnetic field and earthquake prediction. Seismo Electromagnetics: Lithosphere-AtmosphereIonosphere Coupling, Hayakawa M. and O. A. Molchannov (Eds.), TERRAPUB, Tokyo, 463-468.

(IGRF 1945-2000/2005 Model Coefficients 2000, http://nssdc.gsfc.nasa.gov/space/model/models/igrf.html) 